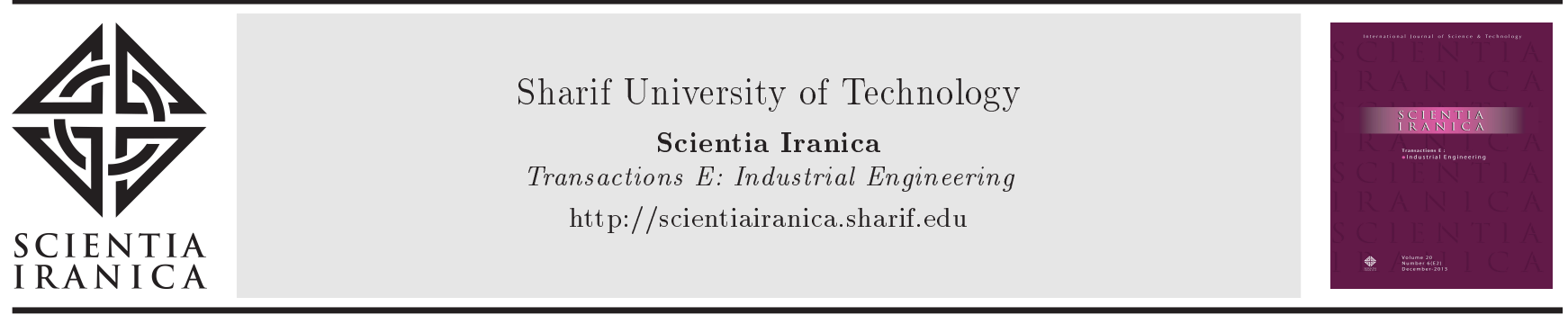

\title{
Bundle pricing, reservation, and refund policies in a two-level supply chain
}

\author{
M. Moeany, A.A. Taleizadeh*, and F. Jolai \\ School of Industrial Engineering, College of Engineering, University of Tehran, Tehran, Iran.
}

Received 12 January 2020; received in revised form 9 April 2020; accepted 18 January 2021

\author{
KEYWORDS \\ Pricing; \\ Product refund policy; \\ Reserved product; \\ Bundling; \\ Return policy; \\ Inventory; \\ Supply chain.
}

\begin{abstract}
Refunding and bundling reservation are known as two popular methods to increase profit and they have gained the attention of many researchers in recent years. One major application of refunding policy emerges in online product sales. In this case, consumers can be refunded by returning goods that are against their interest. Examining three scenarios including refunding, bundle reservation, and refunding along with bundle reservation policies, this study will investigate the viability and performance of a model for each corresponding scenario. Then, the attempt is to compare two refund and bundle reservation pricing policies in a two-level supply chain including one manufacturer and one wholesaler. Then, a combined model including two products is provided. The demand is constant and also, the population-related information about the division of the population into two types of consumers is available: strategic consumers (consumers able to predict the second-stage discount) and myopic consumers (consumers unable to predict the secondstage discount). In addition, the percentage of consumers who refund the product due to regret, inability to install the product, etc. is constant and independent of the amount of refund. It was found that the combined model was optimal and had a higher profit margin than any other policy alone.
\end{abstract}

(C) 2022 Sharif University of Technology. All rights reserved.

\section{Introduction and literature review}

One of the common methods aimed at increasing the profit from products for manufacturers and suppliers is to grant facilities to a buyer based on the possibility of product refund and the increase in demand. In this regard, pricing policies are formed from predicting the increase in demand by studying the parameters of each population. In this field, the effect of the refund amount on the number of sales is significant. The refund policy is applied to many cases. The online

\footnotetext{
*. Corresponding author.

E-mail addresses: m.moeany@ut.ac.ir (M. Moeany);

Taleizadeh@ut.ac.ir (A.A.Taleizadeh)
}

purchasing approach has particularly developed in recent years. In online purchasing from a manufacturing site, the consumer is presented with no opportunity to experience the product before making a decision to purchase it. Therefore, in the refund model, this opportunity is given to the consumer in order to be able to refund the product if not suitable. This assurance will increase demand. Regardless of the value of refund, some consumers tend to return products mainly for some reasons like regret, incapability to install or utilize products, or even their habitual behavior.

Bundle pricing is also known to be one way to increase profits. In this regard, researchers have investigated product bundling types alongside the number of bundles and consumers' background and interest in this subject. Bundle pricing includes two policies: pure bundling policy (merely offering in bundle and 
avoiding single-sail) and mixed bundling policy (using both bundle and single selling methods). Complementary pricing policy is established for a bundle of products that are considered to be a supplement to each other. Of note, complementary goods are those items consumed together and each item complements other items to meet a specific need, e.g., candy and tea, brush, and toothpaste.

Another way to increase profit is pricing based on the product reserved for consumers. This method is widely used by multi-product manufacturers or suppliers. In this method, after purchasing the first product at full price, it is reserved for the consumer at the second stage by providing an intriguing discount which, if desired, would be offered to the consumers. This is to encourage consumers to purchase more. In this section of the paper, the results of recent studies are mentioned with respect to two subjects of refunding and bundling.

\subsection{Pricing with the refund policy}

Assarzadegan and Rasti-Barzoki (2019) [1] introduced CLSC (Closed-Loop Supply Chain) including one producer and two sellers in which sold products can be returned in two groups of defective and non-defective items. In the first scenario, the producer pays retailer 1 , the price of defective products. In the second one, the producer pays the first retailer's price in order to motivate him to offer money back guarantee for defective products. Heydaryan and Taleizadeh (2016a) [2] examined the return pricing policy in a green supply chain. The supply chain produces two types of products, green and non-green products. These products have similar performance with different impact on selling prices and environmental issues. The return policy assumed for each product specifies a value for customers. Different models of pricing strategy and return policy have been developed in both green and non-green modes. Taleizadeh and Heydarian (2017) [3] developed the issue of pricing optimization with the return policy in a two-level supply chain consisting of a supplier and a producer who produces both green and non-green products in both concentrated and decentralized modes. The features of both products are the same in use and performance, but vary in terms of price and environment. The return policy has been considered for both products. The system performance analysis has been conducted in both centralized and decentralized supply chains. Stackelberg game theory and Rubinstein bargaining theory have been used in the centralized and decentralized chains, respectively. The results show that centralized chains increase the profit and demand for both types of products. By increasing the amount of potential demand, the amount of return and the profit of green product increase in centralized and non-centralized chains while the amount of non-green product return is reduced. Heydaryan and Taleizadeh (2016b) [4] developed policies on pricing, return, and supply chain coordination in a two-stage supply chain. Their model was based on a new return policy that depended on the amount of return and product sales price. They developed a combined optimization issue about pricing and return policies, which used the theory of cooperative and non-cooperative games. Giri et al. (2017) [5] developed a multi-producer supply chain model in which producers sell a product through a public retailer channel. In their model, demand at the end of the retail sale depends on retail sale price and product quality. Each producer supplies its product distinctly from other producers. They analyzed the pricing and quality management strategies of producers and retailers in each scenario for centralized and decentralized systems. Noori-daryan and Taleizadeh (2015) [6] developed a low-volume model of production in a threestage supply chain consisting of supplier, producer, and wholesaler under two scenarios. In the first scenario, they considered a return contract between the vendor and the supplier as well as the one between the producer and the wholesaler. In addition, they ignored the return policy between the producer and the wholesaler in the second scenario. Li et al. (2012) [7] examined the roles of optimal policies and pricing in the management of the supply chain of fashion products (for example, a fashion clothing category) according to the product returns between supply chain partners (B2B). They examined the channel performance and optimal policies; two randomized models were designed for centralized and decentralized channels for both new and out-of-season sales management. In a centralized channel, closed solutions were suggested for optimum ordering and pricing decision in the case of new fashion products. Taleizadeh et al. (2017a) [8] examined pricing and solidarity issues analytically in a two-level supply chain with a new upstream input using the return policy, given the importance of the supply chain continuity strategy. They created various mathematical models for different unifying strategies and solved their optimization issues with a game theory approach. Batarfi et al. (2017) [9] studied a leading system and a reverse system consisting of a major manufacturer of equipment and a retailer. A return policy agreement was also considered where dissatisfied consumers might return items by buying a new one. Returned items are collected and only the fixable ones are repaired in accordance with the contractor which are given to consumers at lower prices than new items. A return policy agreement is also used for refurbished equipment. This paper employed a linear demand function in which consumers were sensitive to prices and return policy of the sold items (new and refurbished). Yan and Ke (2015) [10] examined 
two dynamic pricing strategies: matching final prices and delaying the mentioned matching process. These strategies are used by vendors to consider consumer behavior in the market by considering several types of consumers. They analyzed the prices in the season with low sales, purchasing balance, and the prices in the regular sales season using equilibrium theory and induced backward method. The comparison of these two strategies demonstrated that both strategies would enable vendors to increase prices regularly during the sales season. Li et al. (2013) [11] developed a model with a source for the return of sold products. Their study included the following activities: the first distributors on their website describe product information such as appearance and application. Then, customers decide on buying the products on the basis of product descriptions, feelings of need, and price. Customers cannot experience the product until they receive it. When customers receive the product, they will make the final decision within a specified period to either accept or return the product. Li et al. (2017) [12] examined the strategic effect of return policies in a two-channel supply chain in which a manufacturer could supply the products directly to end-consumers as well as indirectly through independent retailers. The manufacturer decides whether to implement the return policy either directly or indirectly or on both channels. When return policy is provided, the cost of returned products must be covered by the relevant channel. They considered four possible strategies, including full refund only in the direct channel, full refund only in the indirect channel, full refund in both channels, and nonrefund in both channels. A joint optimization model of pricing strategies was introduced by Taleizadeh et al. (2017c) [13]. They modeled a supply chain model considering effort decisions, quality levels, and return policies and developed several structures for channel power including retailer Stackelberg, centralized, vertical Nash, third-party Stackelberg, and manufacturer Stackelberg. Taleizadeh et al. (2018b) [14] developed pricing strategies as well as quality consideration and marketing cost of the producer, seller, and thirdparty operating. Over the last decade, the research by Moshtagh and Taleizadeh (2016) [15] coincided with the wider considerable attention to inventory management of manufactured, recovered, and returned items in a closed-loop supply chain. Roy et al. (2016) [16] developed a supply chain including a manufacturer and a seller to find optimum order size, selling price, service level, and promotional measures under uncertain demand. Modak et al. (2016a) [17] stated the concept of recycling of used products to reduce pollution and increase consumption of natural resources as a necessary means to maintain a sustainable life. Modak et al. (2017) [18] developed a two-echelon closed-loop supply chain under recycling, quality consideration, and pricing decisions. Modak et al. (2016b) [19] studied channel coordination and profit division of a three-level chain including producers, distributers, and two retailers. One definite characteristics of the problem was the supplying of lot size of the products that contained a random portion of imperfect quality items by producers. As stated by Taleizadeh et al. (2018a) [20], firms have recently moved towards online purchasing or electronic shopping, but they pointed that there was no way for buyers to confirm the quality of target products, a matter that makes return policy a significant signal for customers to trust the quality of goods since customers are able to return purchased goods and, consequently, are paid back in case of not being satisfied with quality. Moreover, return policy was considered as a function of refund and quality level. The refund amount of the other products affect the return quantity of products. Finally, having provided a numerical example, authors attempted to showcase the profit optimization model. As illustrated by $\mathrm{Xu}$ et al. (2018) [21], the advantages of consumer return policy have been vastly investigated by other researches in this field. Hence, they tried to investigate the potential disadvantages of return policy for retailers. Authors developed an analytic framework to examine the economic impacts of consumers' product return among three groups including customers, retailers, and supply chain. Modak et al. (2016c) [22] developed a coordination problem with pricing in a two-level supply chain including two retailers and a producer. By establishing a manufacturer-Stackelberg game setting, corporate social responsibility was attributed to the manufacturer while cournot and collusion games were to be played by retailers. The above study aimed to explore the impacts of social accountability on making best decisions as well as comparing optimal decisions by retailers. Roy et al. (2015) [23] developed a two-level supply chain including a producer and two retailers in which the demand rate depended on selling price and random customer arrivals. Considering competitors' strategies for retailers, authors analyzed a single-period newspaper to specify the optimal order amount. Retailers' unsold products were repaid at lower prices than the suggested prices from manufacturers. Moreover, retailers encounter paucity since demand is inherently indefinite. Liu et al. (2020) [24] focused on pricing of different items in a chain including a manufacturer and a seller. The significant result of the above study is that "as manufacturers make a direct online selling channel to sell produced items, low-risk products must be considered as well as services which need the lowest level of experience.

\subsection{Pricing with the bundling policy}

Yan and Bandyopadhyay (2011) [25] tried to provide a framework that could help companies obtain optimal 
bundle product categories and pricing strategies that maximize their profits. This study examined a model for maximizing profits. The results indicate that there are optimal bundlings and price strategies; in particular, if a company uses a bundling strategy to sell its products, it should apply the strategy to complementary products and offer a comparatively low price. The values obtained by the bundling strategy with respect to market size and price sensitivity always increase. Managers can use the model framework and advice as well as relevant examples for planning their bundle strategies. As demonstrated by Mesa Arango (2015) [26], bundling services and truck pricing represent key strategic decisions for people working in this area. Benisch and Sandholm (2012) [27] provided a framework to offer discounts on high-profit packed product sales based on previous consumer purchasing data. Several search algorithms are created which identify the prices of maximum profits and product bundling discounts. A more efficient probable evaluation model than the one in the previous work is introduced that considers complementary, replacement, and covariance. Then, a combined search method is presented to fit this model to previous purchase data. The new purchasing information that has been gathered is attached to the evaluation model, thus leading to the emergence of an online technique that continuously markets the prices and discounts of the product bundling. Musa (2017) [28] aimed to examine the effect of a bundling pricing strategy on consumer purchasing decisionmaking in a home-based sharing online product in Makasar, Indonesia. This research was carried out by distributing the questionnaire among 369 people followed by responding to them and random sampling method. As a result of regression analysis, it was found that the application of bundling pricing strategy had a significant impact on purchasing decisions on a homebased sharing online product in Makasar. A bundling strategy with advertisements could help a company achieve higher performance than a bundling strategy without advertising [29]. According to Beladev et al. (2015) [30], adviser systems increase the sales of ecommerce by recommending products related to consumers. Advisers seek to run the company's internet marketing strategy to increase revenue. The production of product bundles is an example of a marketing strategy aimed at meeting the needs and preferences of the consumer while increasing the range of consumer purchases and company income at the same time. Therefore, finding and recommending a personal and optimal bundle is very important. In this paper, a new model of packaging and bundling recommendations was presented which integrated filtering techniques of personal demand functions and price modeling. This model provides a recommended list of a pair of products that can be purchased by the user and the income resulting from the sale of the package and bundle. Chu et al. (2011) [31] argued that multi-product companies could set separate prices for all possible combinations of their products (MB Mix bundling). However, it is not applicable to companies with more than a few products, because the price increases with respect to the number of products exponentially. It was also found that simple pricing strategies were often optimal. Specifically, our study illustrates that the BSP (Bundle-Size Pricing), which depends on the size of the purchased bundles, is more beneficial than providing separate products and tends to benefit from mixed bundling approximately. Jain and Oosterlee (2015) [32] described a practical simulation-based algorithm, called a Stochastic Grid Bundling Method (SGBM), for evaluating multidimensional Bermudan options (functional selection). This method of direct pricing produces an optimal policy on initial pricing as well as a lower bound value for price selection. The benefit of SGBM is that this method can be used for fast approximation (i.e., derivatives due to the base point price such as delta, gamma, etc.) for the Bermudan lightweight options. The computational results of various multidimensional options of the Bermudan point to the simplicity and efficiency of the proposed algorithm. According to Taleizadeh et al. (2017b) [33], the selling of related products is related to the vendor's interactive sales, which is the main factor in revenue management and vendor's costs. Interactive selling is a phenomenon that when demand for products is interconnected, the demand for one of the dependent products automatically causes another demand. In these cases, different sales tactics, such as a Bundling, a bundle of tying products, a combined bundle, etc., are used to sell items. Xiao and Shi (2016) [34] found that with their growing innovation and e-commerce development experience, manufacturers are beginning to sell their products through dual channels: a retail channel and a direct channel. The channel's priority strategy affects supply uncertainty, price, and sales and it thus affects the profitability of the two channels. Considering these factors, the channel priority strategy has been examined in the presence of random operation in both centralized and decentralized environments in this paper. Yang et al. (2015) [35] examined the reservation pricing issue for a two-level fashion supply chain in which a downstream manufacturer with private information at his/her operating costs (low or high costs) reserves an essential component of the upstream supplier before doing the final order. The above authors speculated when the demand forecast has been updated. They found that a new menu of reservation contracts, including a reserve cost with a reservation and final order, could encourage the manufacturer to accurately reflect the cost of his operations. Prasad et al. (2015) [36] concluded that their research originating from the pricing of a product represented 
a two-way profit-making and through the application of this method, the vendor offered two products at an initial price and if the product was purchased, only consumers that had already bought one product rather than two were offered a discount on the second product. Taleizadeh et al. (2019) [37] studied two types of supply chains: (1) centralized supply chain and (2) decentralized supply chain. In this study, the coordination of both mentioned supply chains was regarded as possible and the situation of supplierretailer interaction was considered. As a two-step decision-making model, the supplier initially decides to determine the required capacity for retailers according to prior knowledge and in the second step, the supplier updates information about demand, retailing price, packing cost, and the quantity of ordered packages. In this paper, the supply chain consists of a supplier and a retailer intending to trade two complementary products as a package of production. The package has a shortterm chapter along with random price depending on high uncertainty level.

Depending on sale price and random noise in the market, it was assumed that there was no definite value for this demand rate. In order to determine decisions about the reserved production capacity, the order quantity of bundled products, and the bundleselling price, profit maximization models have been expanded for two supply chains, the centralized and decentralized ones. The applicability of the developed models and solution method was illustrated with a numerical example. Finally, a brief review of the relevant literature is presented in Table 1.

Based on the research literature, none of the researchers have considered the combination of refund and reservation. Therefore, this study develops optimal pricing lower than two policies of refund and bundle reservation in a two-level supply chain with two types of products and the division of society into two types of strategic and myopic consumers with a given coefficient. The questions that may be posed in this research are as follows:

- What is the basis of the division of society into strategic and myopic consumers?

- What is an appropriate structured method that can be used to identify those types of consumers with good approximation?

- Does the developed model have relative advantage and superior ones for online purchases?

The order of this paper is as follows. Section 2 defines the problem. Section 3 presents the analytical models in all the three methods. Section 4 analyzes the sensitivity and comparison of each method in the consumer society. Section 5 summarizes the results and concluding remarks.

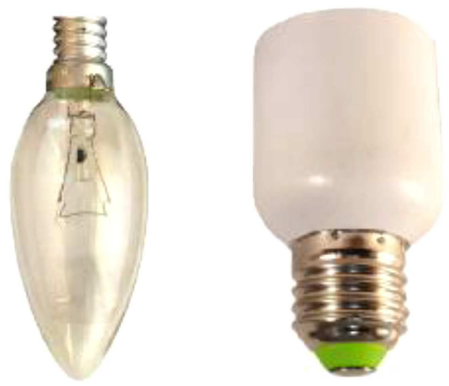

Figure 1. Schematic shape of "60-watt incandescent light" and "E27 to E40 encoder conversion".

\section{Definition of the problem}

In order to define the problem, for example, consider two real-world sales of "E27 to E40 encoder conversion" and "60-watt incandescent light" on a website. Figure 1 shows a schematic shape.

Refund scenario (Scenario 1): Selling any product online on the website at a price of $6.5 \$$, with the possibility of refunding each product at most after one week and paying $5.5 \$$ to the consumer for each refundable product.

Reserve scenario (Scenario 2): Sale of each product at a price of $6.5 \$$ and simultaneously at an unrefundable price of $13 \$$, and offering the second product at a price of $5 \$$ in the second stage without refund only for consumers who buy a product at a price of $6.5 \$$ at the first stage.

Refund and reservation scenario (Scenario 3): The combination of the above conditions implies the sale of each product at a price of $6.5 \$$ and simultaneously at a price of $13 \$$ with the possibility of refunding each product after a maximum of one week and paying the consumer $5.5 \$$ for each refundable product and offering to buy a second product at a price of $5 \$$ in the second stage without the possibility of refunding only for consumers who had already bought a product in the first stage for $6.5 \$$ and had refunded it a week later.

- Scenario 1: The origin of this scenario lies in the sold product refunding. In this scenario, sales managers must determine the product's refundable policy with different consumers responding to the demand and the expectation of refund on the product. They must select an appropriate pricing method.

- Scenario 2: The reservation scenario is based on the pricing of reserved products. This scenario respects two-way profitability, as part of its nature. In this way, the vendor proposes two products at their initial price; when the customers buy the first 
Table 1. Comparison of research works in the literature.

\begin{tabular}{|c|c|c|c|c|c|c|}
\hline Research work & Pricing & Return & Refund & Bundling & Reserve & $\begin{array}{c}\text { Online } \\
\text { purchasing }\end{array}$ \\
\hline Assarzadegan and Rasti-Barzoki (2019) [1] & $\sqrt{ }$ & $\sqrt{ }$ & $\sqrt{ }$ & - & - & - \\
\hline Heydaryan and Taleizadeh (2016a) [2] & $\sqrt{ }$ & $\sqrt{ }$ & $\sqrt{ }$ & - & - & - \\
\hline Taleizadeh and Heydarian (2017) [3] & $\sqrt{ }$ & $\sqrt{ }$ & $\sqrt{ }$ & - & - & - \\
\hline Heydaryan and Taleizadeh (2016b) [4] & $\sqrt{ }$ & $\sqrt{ }$ & $\sqrt{ }$ & - & - & - \\
\hline Giri et al. (2017) [5] & $\sqrt{ }$ & $\sqrt{ }$ & $\sqrt{ }$ & - & - & - \\
\hline Noori-daryan and Taleizadeh (2015) [6] & $\sqrt{ }$ & $\sqrt{ }$ & - & - & - & $\sqrt{ }$ \\
\hline Li et al. (2012) [7] & $\sqrt{ }$ & $\sqrt{ }$ & - & - & - & - \\
\hline Taleizadeh et al. (2017a) [8] & $\sqrt{ }$ & $\sqrt{ }$ & $\sqrt{ }$ & - & - & - \\
\hline Batarfi et al. (2017) [9] & $\sqrt{ }$ & $\sqrt{ }$ & $\sqrt{ }$ & - & - & $\sqrt{ }$ \\
\hline Yan and $\operatorname{Ke}(2015)$ [10] & $\sqrt{ }$ & - & $\sqrt{ }$ & - & - & - \\
\hline Li et al. (2013) [11] & $\sqrt{ }$ & $\sqrt{ }$ & $\sqrt{ }$ & - & - & $\sqrt{ }$ \\
\hline Li et al. (2017) [12] & $\sqrt{ }$ & $\sqrt{ }$ & $\sqrt{ }$ & - & - & $\sqrt{ }$ \\
\hline Taleizadeh et al. (2017c) [13] & $\sqrt{ }$ & $\sqrt{ }$ & - & - & - & - \\
\hline Taleizadeh et al. (2018b) [14] & $\sqrt{ }$ & $\sqrt{ }$ & - & - & - & $\sqrt{ }$ \\
\hline Moshtagh and Taleizadeh (2016) [15] & $\sqrt{ }$ & $\sqrt{ }$ & - & - & - & - \\
\hline Roy et al. (2016) [16] & $\sqrt{ }$ & $\sqrt{ }$ & - & - & - & $\sqrt{ }$ \\
\hline Modak et al. (2016a) [17] & $\sqrt{ }$ & $\sqrt{ }$ & - & - & - & - \\
\hline Modak et al. (2017) [18] & $\sqrt{ }$ & $\sqrt{ }$ & - & - & - & - \\
\hline Modak et al. (2016b) [19] & $\sqrt{ }$ & - & - & - & - & - \\
\hline Taleizadeh et al. (2018a) [20] & $\sqrt{ }$ & $\sqrt{ }$ & $\sqrt{ }$ & $\sqrt{ }$ & - & $\sqrt{ }$ \\
\hline Xu et al. (2018) [21] & $\sqrt{ }$ & - & - & - & - & $\sqrt{ }$ \\
\hline Modak et al. (2016c) [22] & $\sqrt{ }$ & - & - & - & - & - \\
\hline Roy et al. (2015) [23] & $\sqrt{ }$ & $\sqrt{ }$ & - & - & - & - \\
\hline Liu et al. (2020) [24] & $\sqrt{ }$ & - & - & - & - & $\sqrt{ }$ \\
\hline Yan and Bandyopadhyay (2011) [25] & $\sqrt{ }$ & - & - & $\sqrt{ }$ & $\sqrt{ }$ & - \\
\hline Mesa Arango (2015) [26] & $\sqrt{ }$ & $\sqrt{ }$ & $\sqrt{ }$ & $\sqrt{ }$ & - & - \\
\hline Benisch and Sandholm (2012) [27] & $\sqrt{ }$ & - & - & $\sqrt{ }$ & - & - \\
\hline Musa (2017) [28] & $\sqrt{ }$ & - & - & $\sqrt{ }$ & - & - \\
\hline Pan and Zhou (2017) [29] & $\sqrt{ }$ & - & - & $\sqrt{ }$ & - & - \\
\hline Beladev et al. (2015) [30] & $\sqrt{ }$ & - & - & $\sqrt{ }$ & - & - \\
\hline Chu et al. (2011) [31] & $\sqrt{ }$ & - & - & $\sqrt{ }$ & - & - \\
\hline Jain and Oosterlee (2015) [32] & $\sqrt{ }$ & - & - & $\sqrt{ }$ & - & - \\
\hline Taleizadeh et al. (2017b) [33] & $\sqrt{ }$ & - & - & $\sqrt{ }$ & - & - \\
\hline Xiao and Shi (2016) [34] & $\sqrt{ }$ & - & - & - & - & $\sqrt{ }$ \\
\hline Yang et al. (2015) [35] & $\sqrt{ }$ & - & - & - & $\sqrt{ }$ & - \\
\hline Prasad et al. (2015) [36] & $\sqrt{ }$ & - & - & $\sqrt{ }$ & $\sqrt{ }$ & - \\
\hline Taleizadeh et al. (2019) [37] & $\sqrt{ }$ & - & - & $\sqrt{ }$ & - & - \\
\hline This Paper & $\sqrt{ }$ & $\sqrt{ }$ & $\sqrt{ }$ & $\sqrt{ }$ & $\sqrt{ }$ & $\sqrt{ }$ \\
\hline
\end{tabular}

product rather than two, they are entitled to a reserved discount on the second product. This is the reason why the vendor keeps discounting the price of the product in the reserved form. Therefore, the price cannot be reduced in the case of the sales of both products done in the first stage. In this way, if the consumer reasonably expects a discount in the second step and simply delays the purchases until a discount is offered, the price will be reduced in the second stage. Thus, the success of this scenario depends on the percentage of strategic consumers (consumers who can predict the second-stage 


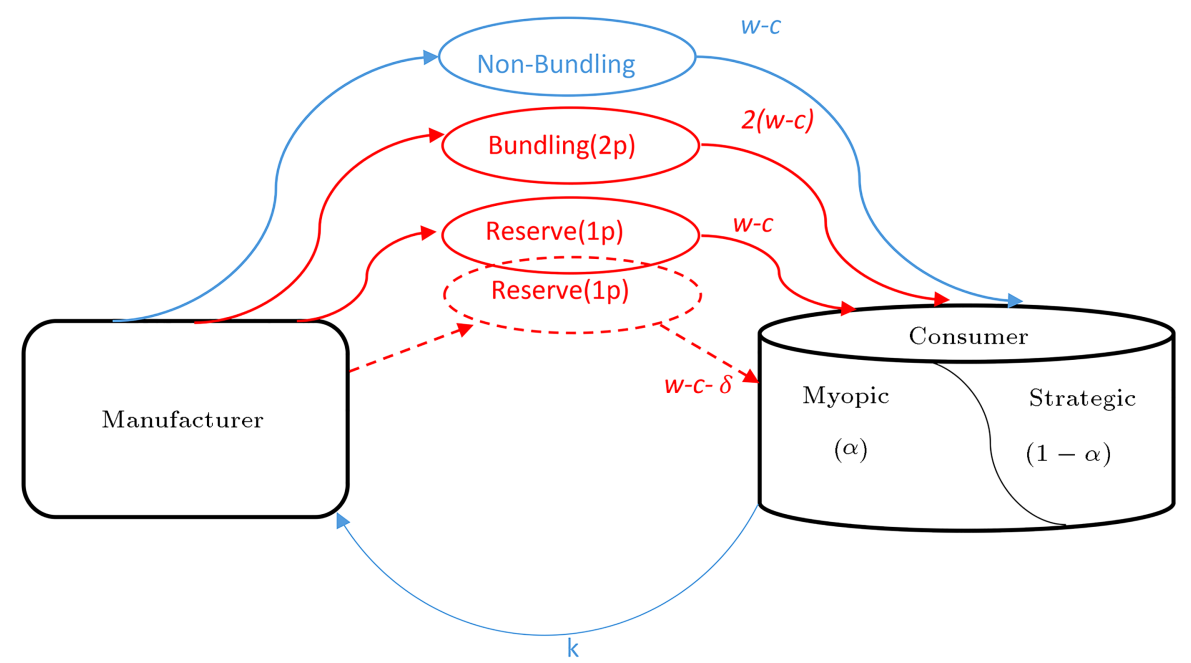

Figure 2. Combination refund and reserve scenario.

discount) and myopic consumers (consumers who cannot predict a second-stage discount). Therefore, collecting additional information about consumers is the key to success of this method.

- Scenario 3: This scenario has been formed based on a combination of two methods. In this method, in addition to the possibility of a product refund, a second product with a discount and no refund is suggested for a consumer who has bought a product in the first stage at the full price and has not been refunded during a specific period. Figure 2 schematically shows a combination of these two scenarios.

Now, the attempt, here, is to compare the above methods in different societies. In this method, consumer recognition in terms of the behavior towards product refund and the possibility of predicting the second stage discount is of particular importance. Therefore, a combined model is presented for the third scenario and it is compared with other scenarios.

\subsection{Assumptions}

The demand is certain and the supply chain is a twolevel structure. It is assumed that the manufacturer has two products available. The values of $\alpha, a, b, c, k$, and $w$ are normal ones and range between 0 and 1 . According to the above parameters, the value of $R$ is between 0 and 1 and always $R \leq D$. The effect of quality is not considered in the refund function. It is assumed that the price of both products is the same.

\subsection{Parameters}

$D \quad$ Demand value

$w \quad$ Value of the sales price of product

$k \quad$ Price of the refund from the sale a Ratio of consumers who demand a refund of the product due to regret, inability to install the product, etc. The potential customers are constant and independent from the amount of refund.

$b \quad$ Sensitivity ratio: The sensitivity of return amount with respect to the amount of refund. It is implied that the higher the value of $K$, the greater the value of $R$

$c \quad$ Production cost of a product

$\delta \quad$ Price discount

$\delta_{e} \quad$ Expected discount amount for strategic consumers

$\alpha \quad$ Predictive factor of consumers, that is, if it is equal to 1 , the whole society cannot make a prediction; if it is zero, the whole society can make it.

\section{Modeling}

In this section, modeling for each scenario is to be continued. These models are formed such that the same parameters in all models are represented by the same symbol.

\subsection{Refund scenario}

$\mathrm{Li}$ et al. (2013) established a model for a refundable product. They provided a model based on product quality and refund parameters. In this scenario, this model has been simplified.

The demand function is defined as follows:

$$
D=f(w, k)=1-w+k,
$$

where minus sign of $w$ indicates a decrease in demand with an increase in the price, and the positive sign of $k$ indicates an increase in demand with an increase in the 
refund amount. In online purchasing, after receiving the product, the consumer decides to use or refund the product within the determined period. The refund function is given as follows:

$$
R=a+b k \text {. }
$$

Considering the above cases, the profit function is given as follows:

$$
\begin{aligned}
\pi= & (w-c) D-k R=(w-c)(1-w+k) \\
& -k(a+b k) .
\end{aligned}
$$

By deriving the profit function compared to $k$ and $w$, the following equations are obtained:

$$
\begin{aligned}
& w=\frac{1+k+c}{2}, \\
& k=\frac{w-c-a}{2 b} .
\end{aligned}
$$

The negative second derivation in both equations indicates that the obtained number is the maximum profit value (see Appendix B). According to the above assumptions, we must consider that there is always the restriction $r$ and $c \leq w \leq 1$. Therefore, the following equations are obtained (see Appendix A):

$$
\begin{aligned}
& w *=\frac{2 b c+2 b-c-a}{4 b-1} \quad b \neq 0.25, \\
& k *=\frac{1-c-2 a}{4 b-1} \quad b \neq 0.25
\end{aligned}
$$

Eq. (8) is shown in Box I. If $b=0.25$, then $c=(1-2 a)$.

\subsection{Reserve scenario}

This model includes both consumers and strategic and myopic consumers. The vendor will maximize his profit function by offering two products. The profit function is defined as follows:

$$
\max [(w-c)+(w-\delta-c) \delta] 2 \alpha(1-w)
$$

$$
\begin{aligned}
& +(1-\alpha)\left\{2(w-c)\left[w-w^{2}+\frac{(1-w)^{2}}{2}+\frac{\delta^{2}}{4}\right]\right. \\
& \left.+2(w-c-\delta)\left[\frac{(1+\delta-w)^{2}-0.5\left(2 \delta-\delta_{e}\right)^{2}}{2}\right]\right\}
\end{aligned}
$$

By deriving the above equation and putting $\delta=\delta_{e}$, we will have the following equations:

$$
\begin{aligned}
& \delta=0.5(w-c) ; \quad \alpha=1 \\
& w=\frac{c+1}{2}+\frac{(1-c)^{2}}{18-2 c+2 \sqrt{(9-c)^{2}+3(1-c)^{2}}} .
\end{aligned}
$$

Otherwise, we have Eq. (12), as shown in Box II.

\subsection{Refund and reserve scenario}

This study examines this scenario separately from the two types of consumers and then, combines them.

\subsubsection{Determination of the demand for myopic consumers}

Here, $\alpha$ coefficient is presented for myopic consumers while the remaining $1-\alpha$ coefficient is given for strategic consumers. The demand in the first stage is equal to $2(1-w+k)$ in the situation, where $k$ is the amount of refund and $0<k<1$ at the price level $w$; moreover, that in the second stage is equal to $2(1-w+R)$ at the price level $w-\delta$. It is assumed that the actual amount of the second stage discount is equal to $\delta$. Then, we will have:

$$
\begin{aligned}
\pi= & \alpha\{[2(w-c)(1-w+k)+2(w-\delta-c) \\
& (1-w+k) \delta]-2 k(a+k b)\} .
\end{aligned}
$$

\subsubsection{Determination of the demand for strategic consumers}

Strategic consumers usually hold a rational expectation of discount in the second stage. In this case, $\delta_{e}$

$$
\pi *=\frac{4 b^{2} c^{2}+4 a^{2} b-8 b^{2} c-b c^{2}+4 b^{2}-a^{2}+4 a b c-4 a b+2 b c-a c+a-b}{(4 b-1)^{2}} \quad b \neq 0.25
$$

Box I

$$
\delta=\frac{4 w-4+\sqrt{16(1-w)^{2}-2(1-\alpha)^{2}(1-w)^{2}+4(w-c)(1-\alpha)(1-w)}}{1-\alpha}
$$




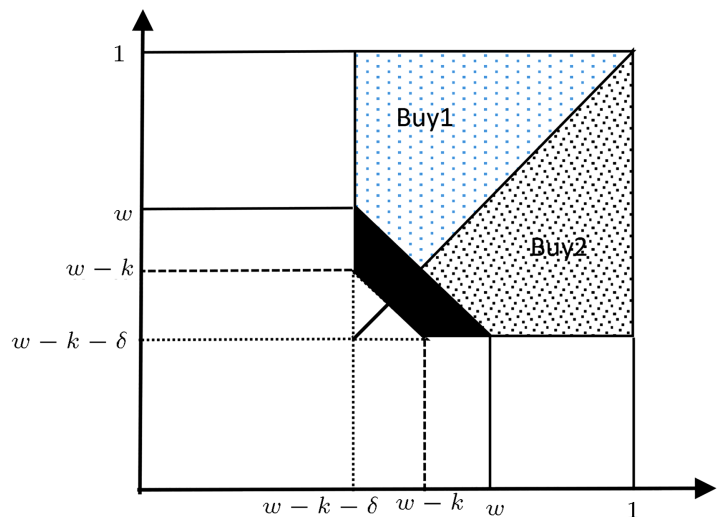

Figure 3. Demand diagram in the first stage.

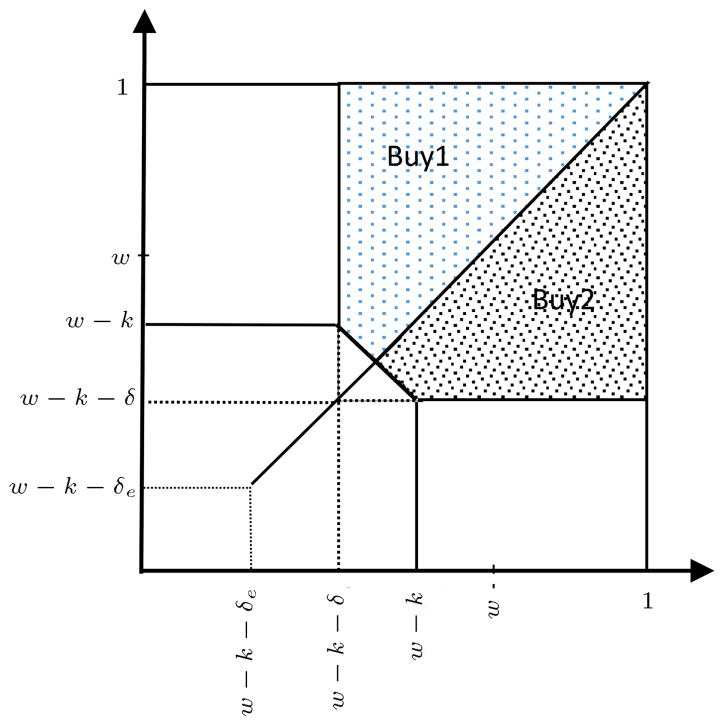

Figure 4. Demand diagram in the second stage.

is the expected value of the discount for this type of consumers. Figure 3 shows the structure of the demand function for the first sales stage. Unlike myopic consumers, strategic consumers do not buy the first two products in the first stage. Demand in the first stage is equal to:

$$
\left[(w-k)(1-w+k)+\frac{(1-w+k)^{2}}{2}+\frac{\delta^{2}}{4}\right],
$$

at the price of $w-c$, since demand in a non-refundable state is less than this value. As shown in Figure 3, the hatchback section shows the demand in a situation where refunding of products is not allowed; however, if the assumption of refund is accepted, the black part will be added to the demand. The demand is obtained in the second stage according to Figure 4. This demand is equal to:

$$
\frac{(1-w+\delta+k)^{2}-0.5\left(2 \delta-\delta_{e}\right)^{2}}{2},
$$

provided at price $w-c-\delta$.

\subsubsection{Combination of profits from both types of consumers (strategic and myopic)}

The profit function for the combination of both types of customers is shown in Eq. (14):

$$
\begin{aligned}
\pi= & \max \alpha\{[2(w-c)(1-w+k)+2(w-\delta-c) \\
& (1-w+k) \delta]-2 k(a+k b)\} \\
& +(1-\alpha)\{2(w-c)[(w-k)(1-w+k) \\
& \left.+\frac{(1-w+k)^{2}}{2}+\frac{\delta^{2}}{4}\right]+2(w-\delta-c) \\
& {\left[\frac{(1-w+\delta+k)^{2}-0.5\left(2 \delta-\delta_{e}\right)^{2}}{2}\right] } \\
& -2 k(a+k b)\} .
\end{aligned}
$$

It is assumed that $a$ and $b$ are the percentages of consumers who are accustomed to refunding and a group of consumers who are encouraged to refund the items; accordingly to the refund amount is constant in both stages.

\section{A numerical example, sensitivity analysis, and managerial insights}

Here, numerical examples are examined based on hypothetical data to determine the parameters of each scenario in ascending order and the best conditions for the profit function. The scenarios in order are examined.

\subsection{Refund scenario}

The data of this scenario is that the parameters $a, b$, and $c$ have been assigned 0.05 to 0.85 , respectively, with a 0.05 range. Based on the results of this scenario, the values of $k, w$, and $\pi$ have been calculated according to Table 2. The diagram of the profit trend compared to the cost is shown in Figure 5. This diagram indicates that with an increase in $c$, the profit product decreases exponentially. It seems logical that the profit margin increases if the product cost is reduced. Figure 6 also shows changes in profit by changing the ratio of the sensitivity of return amount with respect to refund value, that is parameter $b$.

The data of this diagram are available in Table 3 and they were obtained upon increasing 0.05 from 0.04 to 0.84 of the above parameters. As is clear, the best way to increase profits is for $b$ to be about $50 \%$. To put it differently, if the population is such that $50 \%$ of the refund is proportional to the refund amount, the maximum profit is ensured. 
Table 2. Optimal profit variation with respect to cost.

\begin{tabular}{cccccc}
\hline $\boldsymbol{c}$ & $\boldsymbol{a}$ & $\boldsymbol{b}$ & $\boldsymbol{k}^{*}$ & $\boldsymbol{w}^{*}$ & $\boldsymbol{\pi}^{*}$ \\
\hline 0.05 & 0.05 & 0.5 & 0.85 & 0.95 & 0.4065 \\
0.1 & 0.05 & 0.5 & 0.8 & 0.95 & 0.3627 \\
0.15 & 0.05 & 0.5 & 0.75 & 0.95 & 0.3215 \\
0.2 & 0.05 & 0.5 & 0.7 & 0.95 & 0.2827 \\
0.25 & 0.05 & 0.5 & 0.65 & 0.95 & 0.2464 \\
0.3 & 0.05 & 0.5 & 0.6 & 0.95 & 0.2127 \\
0.35 & 0.05 & 0.5 & 0.55 & 0.95 & 0.1814 \\
0.4 & 0.05 & 0.5 & 0.5 & 0.95 & 0.1526 \\
0.45 & 0.05 & 0.5 & 0.45 & 0.95 & 0.1264 \\
0.5 & 0.05 & 0.5 & 0.4 & 0.95 & 0.1026 \\
0.55 & 0.05 & 0.45 & 0.44 & 0.99 & 0.089 \\
0.6 & 0.05 & 0.45 & 0.38 & 0.99 & 0.0682 \\
0.65 & 0.05 & 0.45 & 0.31 & 0.98 & 0.0502 \\
0.7 & 0.05 & 0.45 & 0.25 & 0.98 & 0.0351 \\
0.75 & 0.05 & 0.45 & 0.19 & 0.97 & 0.0227 \\
0.8 & 0.05 & 0.4 & 0.17 & 0.98 & 0.0142 \\
0.85 & 0.05 & 0.35 & 0.13 & 0.99 & 0.0072 \\
\hline & & & & &
\end{tabular}

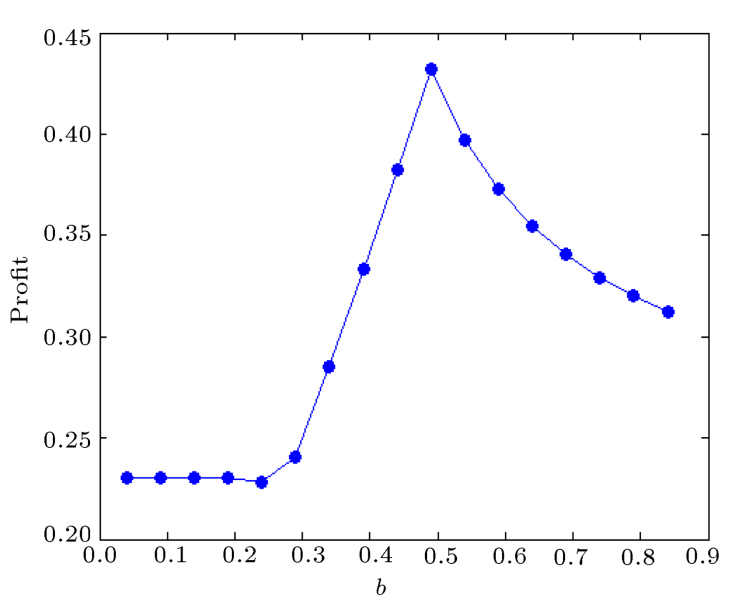

Figure 5. Profit changes diagram compared to $b$.

\subsection{Reserve scenario}

The data from this scenario shows that the parameters $a, b$, and $c$ have been assigned 0.05 to 0.95 , respectively, with a 0.07 range. Based on the results of this scenario, the values $k, w$, and $\pi$ have been calculated, as shown in Table 4. Figure 7 shows the rate of profit based on the population's predictive coefficient, that is, the parameter $\alpha$. The diagram shows that if the myopic consumers constitute the population as a whole, increase in profits will ensue; if $90 \%$ of the population be strategic consumers, the profit will be maximized.

Figure 8 shows the amount of profit compared to the cost changes, indicating that the profit will increase

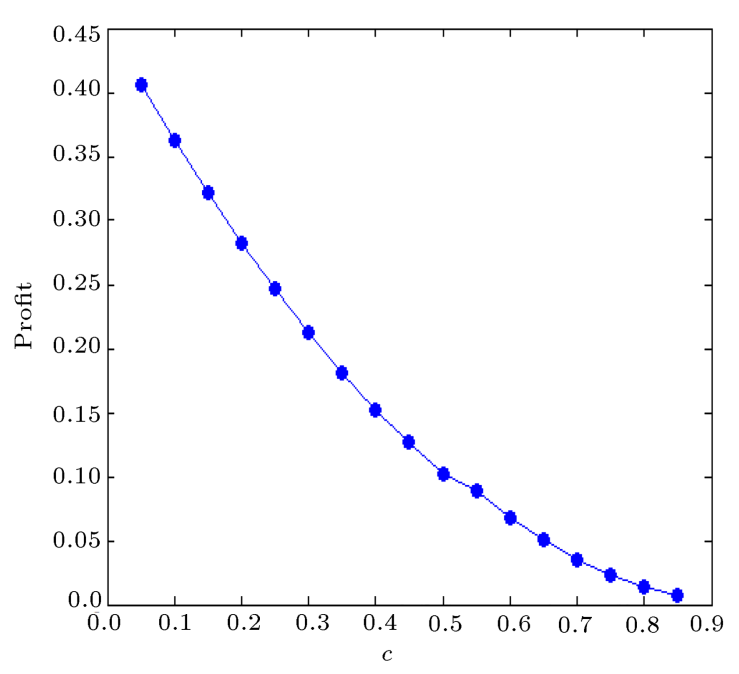

Figure 6. Profit changes diagram compared to $c$.

Table 3. Optimal profit variations compared to $b$.

\begin{tabular}{cccccc}
\hline $\boldsymbol{b}$ & $\boldsymbol{a}$ & $\boldsymbol{c}$ & $\boldsymbol{k}^{*}$ & $\boldsymbol{w}^{*}$ & $\boldsymbol{\pi}^{*}$ \\
\hline 0.04 & 0.49 & 0.04 & 0.02 & 0.53 & 0.2303 \\
0.09 & 0.49 & 0.04 & 0.03 & 0.54 & 0.2302 \\
0.14 & 0.49 & 0.04 & 0.05 & 0.54 & 0.2302 \\
0.19 & 0.49 & 0.04 & 0.08 & 0.56 & 0.23 \\
0.24 & 0.49 & 0.04 & 0.5 & 0.77 & 0.2279 \\
0.29 & 0.44 & 0.04 & 0.5 & 0.77 & 0.2404 \\
0.34 & 0.34 & 0.04 & 0.78 & 0.91 & 0.2848 \\
0.39 & 0.24 & 0.04 & 0.86 & 0.95 & 0.3333 \\
0.44 & 0.14 & 0.04 & 0.89 & 0.97 & 0.3825 \\
0.49 & 0.04 & 0.04 & 0.92 & 0.98 & 0.4321 \\
0.54 & 0.04 & 0.04 & 0.76 & 0.9 & 0.3973 \\
0.59 & 0.04 & 0.04 & 0.65 & 0.84 & 0.3728 \\
0.64 & 0.04 & 0.04 & 0.56 & 0.8 & 0.3545 \\
0.69 & 0.04 & 0.04 & 0.5 & 0.77 & 0.3404 \\
0.74 & 0.04 & 0.04 & 0.45 & 0.74 & 0.3292 \\
0.79 & 0.04 & 0.04 & 0.41 & 0.72 & 0.32 \\
0.84 & 0.04 & 0.04 & 0.37 & 0.71 & 0.3124 \\
\hline
\end{tabular}

as the cost declines. This is the same as that in the previous scenario. The data sets are shown in Table 5.

Figure 9 shows that the amount of profit, compared to the price of the product, specifies the best selling price at $50 \%$. The data in this diagram are presented in Table 6.

\subsection{Refund and reserve scenario}

The data for this scenario is that the parameters $a, b$, and $c$ have been set to 0.05 to 0.95 , respectively, with a value of 0.1 . Based on the results of this scenario, the values $k, w$, and $\pi$ have been calculated, as shown in 
Table 4. Optimal profit variations based on $\alpha$.

\begin{tabular}{ccccc}
\hline $\boldsymbol{\alpha}$ & $\boldsymbol{c}$ & $\boldsymbol{w}$ & $\boldsymbol{\delta}$ & $\boldsymbol{\pi}^{*}$ \\
\hline 0.05 & 0.05 & 0.61 & 0.18 & 0.4783 \\
0.12 & 0.05 & 0.61 & 0.18 & 0.4802 \\
0.19 & 0.05 & 0.61 & 0.19 & 0.482 \\
0.26 & 0.05 & 0.61 & 0.2 & 0.4839 \\
0.33 & 0.05 & 0.61 & 0.21 & 0.4856 \\
0.4 & 0.05 & 0.61 & 0.21 & 0.4873 \\
0.47 & 0.05 & 0.61 & 0.22 & 0.489 \\
0.54 & 0.05 & 0.54 & 0.19 & 0.4912 \\
0.61 & 0.05 & 0.54 & 0.2 & 0.4935 \\
0.68 & 0.05 & 0.54 & 0.2 & 0.4959 \\
0.75 & 0.05 & 0.54 & 0.21 & 0.4982 \\
0.82 & 0.05 & 0.54 & 0.22 & 0.5004 \\
0.89 & 0.05 & 0.54 & 0.23 & 0.5027 \\
\hline
\end{tabular}

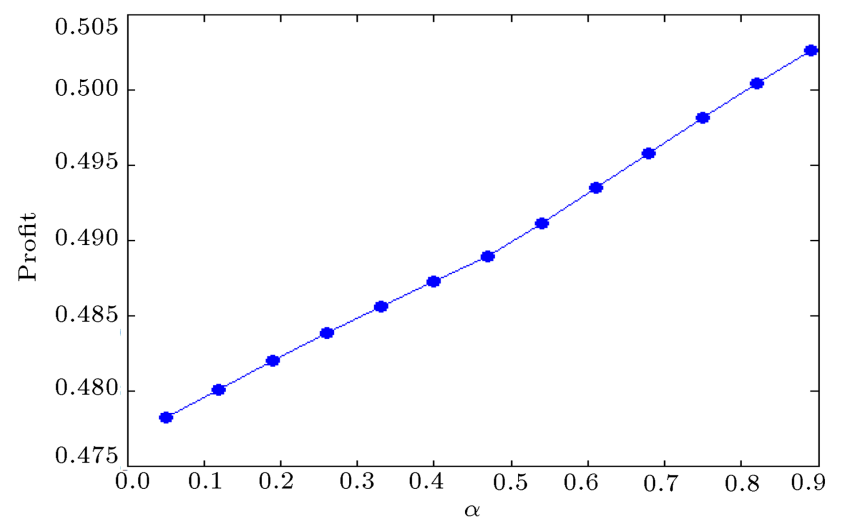

Figure 7. Diagram of profit value based on the coefficient of $\alpha$.

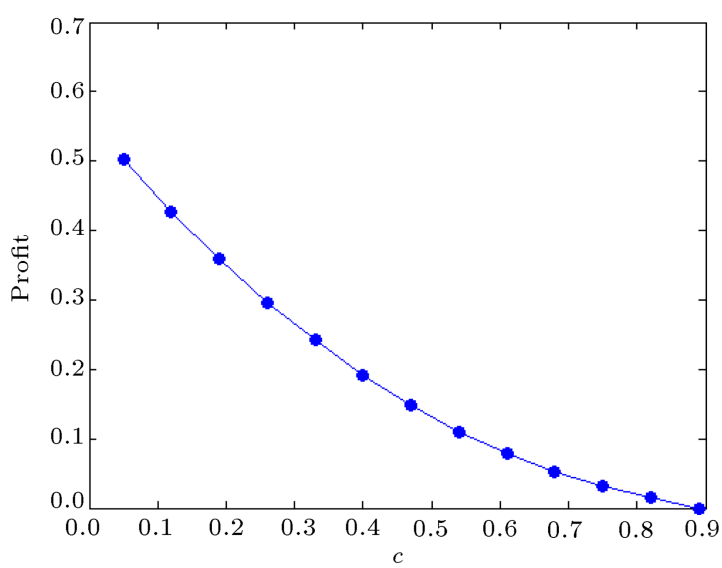

Figure 8. Profit value diagram according to the cost of the product.

Table 7. Figure 10 shows the profit diagram in terms of refund value.

As indicated by this diagram, increasing refund will cause an increase in the profit. Of course, the rate of these changes, as seen, will be slower in refund endpoints.

Diagram in Figure 11 shows the profit earned from
Table 5. Optimal profit variations compared to changes in the cost of the product.

\begin{tabular}{ccccc}
\hline $\boldsymbol{c}$ & $\boldsymbol{\alpha}$ & $\boldsymbol{w}$ & $\boldsymbol{\delta}$ & $\boldsymbol{\pi}^{*}$ \\
\hline 0.05 & 0.89 & 0.54 & 0.23 & 0.5027 \\
0.12 & 0.89 & 0.61 & 0.23 & 0.4272 \\
0.19 & 0.89 & 0.61 & 0.2 & 0.36 \\
0.26 & 0.89 & 0.68 & 0.2 & 0.2961 \\
0.33 & 0.89 & 0.68 & 0.17 & 0.2425 \\
0.4 & 0.89 & 0.68 & 0.13 & 0.1906 \\
0.47 & 0.89 & 0.75 & 0.13 & 0.1493 \\
0.54 & 0.89 & 0.75 & 0.1 & 0.11 \\
0.61 & 0.89 & 0.82 & 0.1 & 0.0794 \\
0.68 & 0.89 & 0.82 & 0.06 & 0.052 \\
0.75 & 0.89 & 0.89 & 0.07 & 0.0318 \\
0.82 & 0.89 & 0.89 & 0.03 & 0.0156 \\
\hline
\end{tabular}

Table 6. Optimal profit variations compared to the price of product.

\begin{tabular}{ccccc}
\hline $\boldsymbol{k}$ & $\boldsymbol{\alpha}$ & $\boldsymbol{c}$ & $\boldsymbol{\delta}$ & $\boldsymbol{\pi}^{*}$ \\
\hline 0.05 & 0.95 & 0.05 & 0.25 & 0.553547 \\
0.15 & 0.95 & 0.05 & 0.35 & 0.663228 \\
0.25 & 0.95 & 0.05 & 0.35 & 0.781303 \\
0.35 & 0.95 & 0.05 & 0.35 & 0.921966 \\
0.45 & 0.95 & 0.05 & 0.35 & 1.061028 \\
0.55 & 0.95 & 0.05 & 0.35 & 1.199691 \\
0.65 & 0.95 & 0.05 & 0.25 & 1.351197 \\
0.75 & 0.95 & 0.05 & 0.15 & 1.462378 \\
0.85 & 0.95 & 0.05 & 0.05 & 1.522884 \\
\hline
\end{tabular}

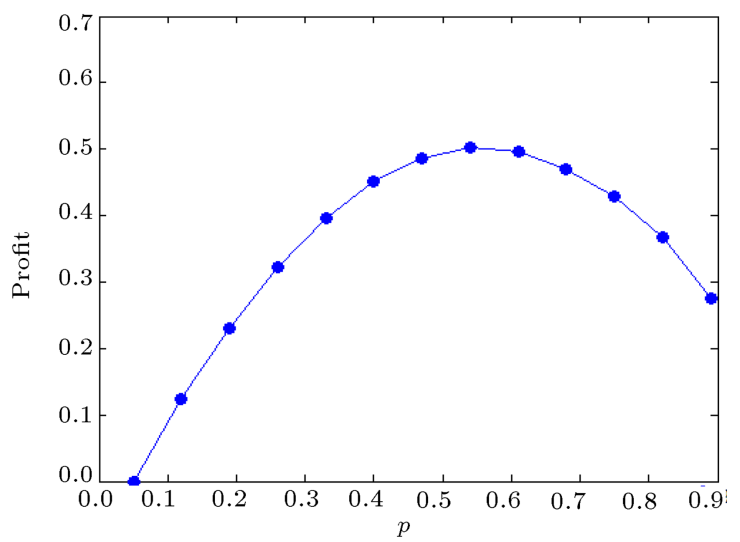

Figure 9. Diagram of profit according to product price.

the discount on the second product. The impact of this factor alone is that by reducing the amount of discount, the profit increases and there is an inflection point in this diagram, implying that by keeping other parameters constant, the rate of profit remains changed in the areas of about $70 \%$. The data in this diagram are shown in Table 8. 
Table 7. Optimal profit variations compared to the refund value.

\begin{tabular}{ccccc}
\hline $\boldsymbol{w}$ & $\boldsymbol{\alpha}$ & $\boldsymbol{c}$ & $\boldsymbol{\delta}$ & $\boldsymbol{\pi}^{*}$ \\
\hline 0.12 & 0.89 & 0.05 & 0.01 & 0.1234 \\
0.19 & 0.89 & 0.05 & 0.05 & 0.2305 \\
0.26 & 0.89 & 0.05 & 0.08 & 0.3215 \\
0.33 & 0.89 & 0.05 & 0.12 & 0.3954 \\
0.4 & 0.89 & 0.05 & 0.16 & 0.4509 \\
0.47 & 0.89 & 0.05 & 0.19 & 0.487 \\
0.54 & 0.89 & 0.05 & 0.23 & 0.5027 \\
0.61 & 0.89 & 0.05 & 0.27 & 0.4967 \\
0.68 & 0.68 & 0.05 & 0.28 & 0.469 \\
0.75 & 0.05 & 0.05 & 0.26 & 0.428 \\
0.82 & 0.05 & 0.05 & 0.29 & 0.3675 \\
0.89 & 0.05 & 0.05 & 0.3 & 0.2752 \\
\hline
\end{tabular}

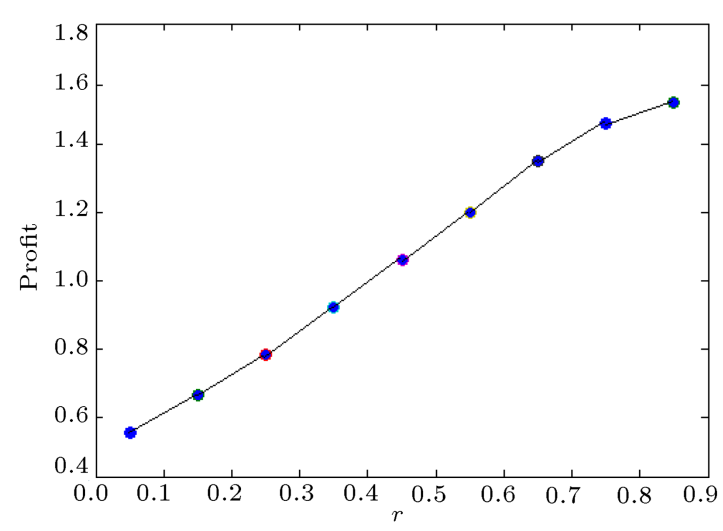

Figure 10. Profit diagram in terms of refund value.

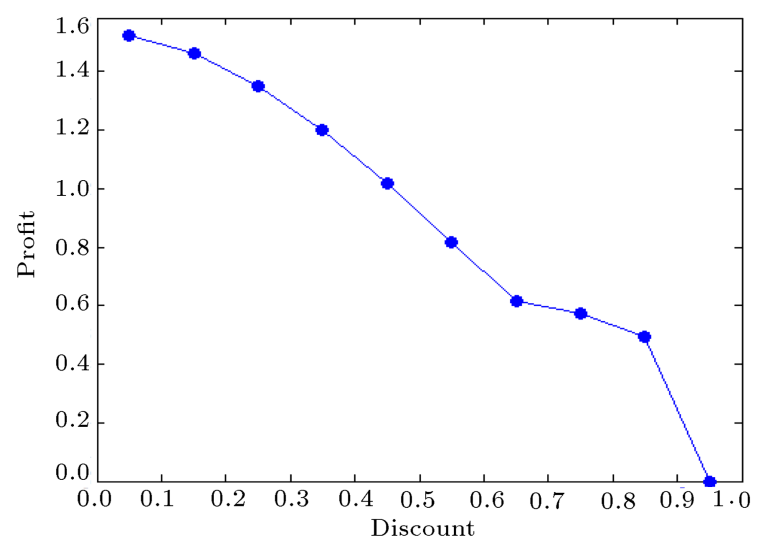

Figure 11. Diagram of profit in terms of a discount.

\subsection{Comparison of methods}

As shown in Tables 9 and 10, the values of the maximum profit of each scenario are compared to different values of $p$ and $c$. These values indicate that the refund and reserve scenario significantly maximizes the profit function compared to the other two scenarios.

Figure 12 examines the maximum profit obtained
Table 8. Optimal profit variations compared to discount (some data).

\begin{tabular}{ccccc}
\hline $\boldsymbol{k}$ & $\boldsymbol{\alpha}$ & $\boldsymbol{c}$ & $\boldsymbol{\delta}$ & $\boldsymbol{\pi}^{*}$ \\
\hline 0.05 & 0.95 & 0.05 & 0.25 & 0.553547 \\
0.15 & 0.95 & 0.05 & 0.35 & 0.663228 \\
0.25 & 0.95 & 0.05 & 0.35 & 0.781303 \\
0.35 & 0.95 & 0.05 & 0.35 & 0.921966 \\
0.45 & 0.95 & 0.05 & 0.35 & 1.061028 \\
0.55 & 0.95 & 0.05 & 0.35 & 1.199691 \\
0.65 & 0.95 & 0.05 & 0.25 & 1.351197 \\
0.75 & 0.95 & 0.05 & 0.15 & 1.462378 \\
0.85 & 0.95 & 0.05 & 0.05 & 1.522884 \\
\hline
\end{tabular}

Table 9. Comparison of three scenarios for different product costs.

\begin{tabular}{cccc}
\hline $\boldsymbol{c}$ & $\begin{array}{c}\text { Refund } \\
\text { scenario }\end{array}$ & $\begin{array}{c}\text { Reserve } \\
\text { scenario }\end{array}$ & $\begin{array}{c}\text { Refund and reserve } \\
\text { scenario }\end{array}$ \\
\hline 0.1 & 0.405 & 0.448239 & 1.62 \\
0.2 & 0.32 & 0.349969 & 1.44 \\
0.3 & 0.326667 & 0.263343 & 1.26 \\
0.4 & 0.24 & 0.192643 & 1.08 \\
0.5 & 0.175 & 0.128881 & 0.9 \\
0.6 & 0.106667 & 0.083746 & 0.72 \\
0.7 & 0.135 & 0.042084 & 0.54 \\
0.8 & 0.06 & 0.020468 & 0.36 \\
0.9 & 0.015 & $2.66 \mathrm{E}-17$ & 0.18 \\
\hline
\end{tabular}

Table 10. Comparison of three scenarios at different sales prices.

\begin{tabular}{cccc}
\hline $\boldsymbol{w}$ & $\begin{array}{c}\text { Refund } \\
\text { scenario }\end{array}$ & $\begin{array}{c}\text { Reserve } \\
\text { scenario }\end{array}$ & $\begin{array}{c}\text { Refund and reserve } \\
\text { scenario }\end{array}$ \\
\hline 0.1 & - & 0.181368 & 1.8 \\
0.2 & - & 0.330342 & 1.62 \\
0.3 & - & 0.444987 & 1.44 \\
0.4 & - & 0.522115 & 1.26 \\
0.5 & 0.25 & 0.558534 & 1.08 \\
0.6 & 0.28 & 0.551044 & 0.9 \\
0.7 & 0.29 & 0.502694 & 0.72 \\
0.8 & 0.34 & 0.424745 & 0.54 \\
0.9 & 0.41 & 0.283746 & 0.36 \\
\hline
\end{tabular}

at different values of parameter $c$. As is clear, the scenario of reserve and refund outperforms other scenarios. Figure 13 shows three scenarios concerning different values of the price of the product or the parameter $w$, being clear that the third scenario is better than the others. 


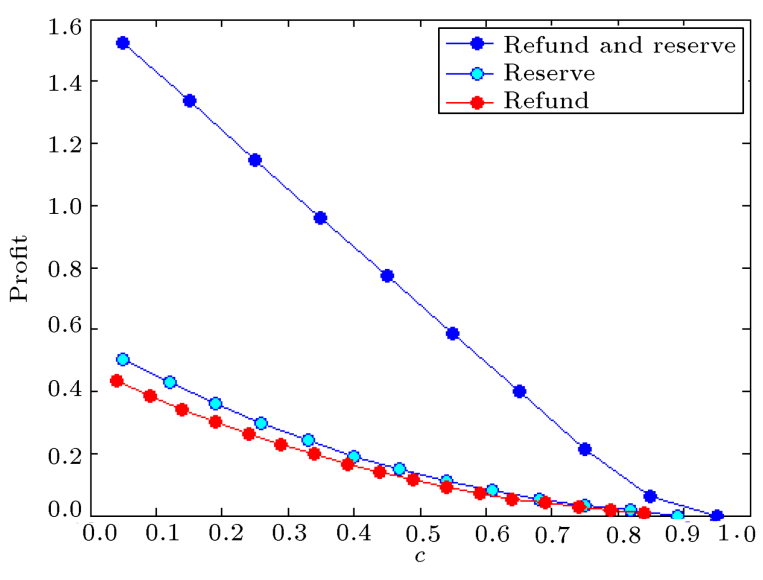

Figure 12. Review of three scenarios for different costs.

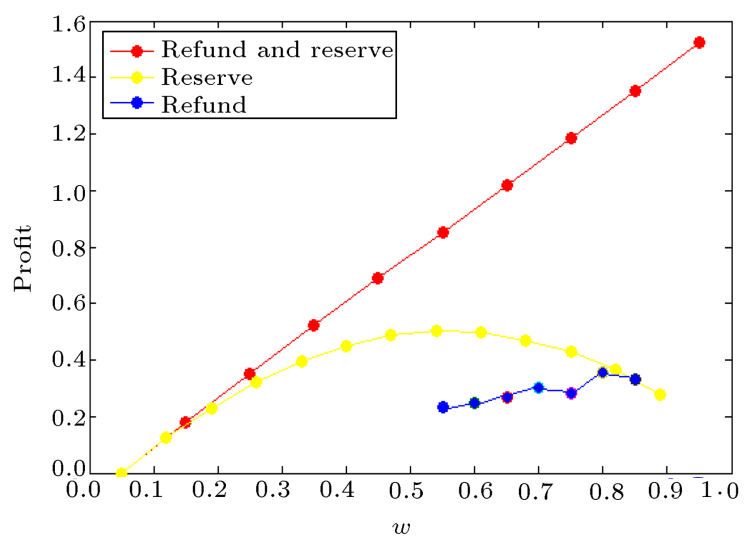

Figure 13. Review of three scenarios for different product sales prices.

\subsection{Managerial insights}

The subject matter of the current research can be applied to many industries like auto parts manufacturing, food industry, and clothing. For all the mentioned industries, there is a need for companies to know the following issues: how to identify $\alpha$ (the predictive factor of consumers)? what products receive benefit from this method? how to determine the time period for secondary discount? does this method work better at a specific time of selling? what are success factors in this method? How to determine $b$ (the sensitivity ratio of the number of refunded consumers to the amount of refund)? We have achieved the following managerial insights as the most significant ones:

1. As shown in Figure 6, the parameter $\alpha$, which is the percent of strategic customers, represents the division of population. Profit margins will rise when myopic consumers increase in number.

Such products as seasonal products or university term books that should be purchased at the beginning of the semester by myopic consumers for possible reasons like shortage of time, despite the discount prediction, will increase profits. Certain policies including change in time discounts may mislead strategic consumers, thereby increasing the number of myopic consumers and bringing about increased profitability. Another factor that increases the number of strategic consumers is consumer loyalty. In other words, due to the quality, good services, and refund, if some consumers transform from simple consumers into loyal ones, the number of consumers in the population increases. To determine the predictive factor of consumers, it suffices to consider customers' database and corresponding records of their history;

2. The presented method applies to companies whose products enjoy high variety and it involves classifying the products and providing a bundle with a policy of refund. However, it works better for complementary products. Also, this method is viably applicable to companies whose products are not outdated. The online sales approach is a tool to help increase demand and the number of sales raises due to the policy of refund;

3. Secondary discount must have a certain and appropriate time duration so as to encourage consumers to buy the proposed products. This time interval must not be too long as to cause a misunderstanding on the part of consumers who might feel that there is no need to consume anymore; by the same logic, it must not be too short in duration as to make them feel cheated;

4. It is worth mentioning that this method is also very useful in some companies that use the discount method and reduced price to make up the sales at special times and on special occasions such as Christmas or Norouz holidays;

5. One main factor to guarantee the accomplishment of this method is employing appropriate advertising and informing approaches for target population of consumers;

6. According to Figure 5, the parameter $b$, which indicates the sensitivity parameter of the population to the amount of the refund, brings about the highest amount of profit when about $50 \%$ of the rational consumers relate the amount of the refund to the refund price. This means that this method is applicable to those communities that are introduced by product advertisements and the product refund policy is communicated to consumers. Meanwhile, proper servicing of the product refund chain enhances this parameter and approaches the appropriate level. The application of consumer loyalty activities also brings this index closer to the desired level. In order to estimate this parameter, statistical methods can be used. 


\section{Conclusion and future development}

This study presented a model based on refundable products. After obtaining the optimal solution to this model, another model based on the sales of two products in the second-order reserve was investigated in terms of performance by considering the division of consumer population into two subsets of the strategic and myopic consumers. The corresponding modeling was performed and the optimal values were determined. This model was kind of bundling. Then, it was demonstrated that a combined model that could study the parameters of the population and determine the degree of the predictability of the population towards the discount in multi-product companies and also the study of the parameters of population regarding the refund function was achievable by combining the two methods of pricing based on the reserved product and the refund of the product. This study proved that the combined model could enhance the profit function for each method alone. The combined scenario along with numerical examples of each scenario was examined to function better and the results of the scenarios were compared, thus indicating the supremacy of the combined scenario. As observed earlier, the combined model acts far better than any model individually. Moreover, the introduced model is practically applicable to various industries. There is no evidence on the joint consideration of both areas among researches in the literature.

Given that the current study was limited to having two types of products, it is suggested for future exploration that the adopted model be developed under greater product diversity. Moreover, it is possible to consider the element of quality in the model. Increasing the supply chain level can also be another option in this regard. Considering different prices for product bundling rather than identical prices as it was assumed in current research is another idea to develop this study. Another limitation of this study lies in the deterministic values of demand, which can be suggested as an approach for future studies. This study can go through further development in an uncertain space or be mingled with fuzzy theory. In addition, considering a bi-level supply chain, three-level supply chains might be of interest. In order to expand the proposed model, Markowitz model is used where demand variation is to reach minimum through at least average profit limitation.

\section{References}

1. Assarzadegan, P. and Rasti-Barzoki, M. "A game theoretic approach for pricing under a return policy and a money back guarantee in a closed loop supply chain", International Journal of Production Economics, 222, 107486 (2020).
2. Heydaryan, H. and Taleizadeh, A.A. "Pricing strategy and return policy of one-echelon green supply chain under both green and hybrid productions", Journal of Industrial and Systems Engineering, 9, pp. 17-29 (2016a).

3. Taleizadeh, A.A. and Heydarian, H. "Pricing, refund, and coordination optimization in a two stages supply chain of green and non-green products under hybrid production mode", Journal of Remanufacturing, 7(1), pp. $49-76$ (2017).

4. Heydaryan, H. and Taleizadeh, A.A. "Pricing strategy, return policy and coordination in a two-stage supply chain", International Journal of Systems Science: Operations and Logistics, 4(4), pp. 384-391 (2016b).

5. Giri, B.C., Roy, B., and Maiti, T. "Multi-manufacturer pricing and quality management strategies in the presence of brand differentiation and return policy", Computers and Industrial Engineering, 105, pp. 146157 (2017).

6. Noori-daryan, M. and Taleizadeh, A.A. "Optimizing pricing and ordering strategies in a three-level supply chain under return policy", 11th International Industrial Engineering Conference (2015).

7. Li, Y., Wei, C., and Cai, X. "Optimal pricing and order policies with $\mathrm{B} 2 \mathrm{~B}$ product returns for fashion products", International Journal of Production Economics, 135(2), pp. 637-646 (2012).

8. Taleizadeh, A.A., Soleymanfar, V.R., and Choi, T.M. "Optimal pricing and alliance strategy in a retailerled supply chain with the return policy: a gametheoretic analysis", Information Sciences, 420, pp. 466-489 (2017a).

9. Batarfi, R., Jaber, M.Y., and Aljazzar, S.M. "A profit maximization for a reverse logistics dual-channel supply chain with a return policy", Computers and Industrial Engineering, 106, pp. 58-82 (2017).

10. Yan, B. and Ke, C. "Two strategies for dynamic perishable product pricing to consider in strategic consumer behaviour", International Journal of Production Research, 56(5), pp. 1757-1772 (2015).

11. Li, Y., Xu., L., and Li, D. "Examining relationships between the return policy, product quality, and pricing strategy in online direct selling", International Journal of Production Economics, 144(2), pp. 451-460 (2013).

12. Li, G., Li, L., Sethi, S.P., et al. "Return strategy and pricing in a dual-channel supply chain", International Journal of Production Economics, 215, pp. 153-164 (2018).

13. Taleizadeh, A.A., Moshtagh, M.S., and Moon, I. "Optimal decisions of price, quality, effort level and return policy in a three-level closed-loop supply chain based on different game theory approaches", European Journal of Industrial Engineering, 11(4), pp. 486-525 (2017c). 
14. Taleizadeh, A.A., Moshtagh, M.S., and Moon, I. Pricing, "Product quality, and collection optimization in a decentralized closed-loop supply chain with different channel structures: Game theoretical approach", Journal of Cleaner Production, 189, pp. 406-431 (2018b).

15. Moshtagh, M.S. and Taleizadeh, A.A. "Stochastic integrated manufacturing and remanufacturing model with shortage, rework and quality based return rate in a closed loop supply chain", Journal of Cleaner Production, 141, pp. 1548-1573 (2016).

16. Roy, A., Sana, S.S., and Chaudhuri, K. "Joint decision on EOQ and pricing strategy of a dual channel of mixed retail and e-tail comprising of single manufacturer and retailer under stochastic demand", Computers and Industrial Engineering, 102, pp. 423-434 (2016).

17. Modak, N.M., Panda, S., and Sana, S.S. "Twoechelon supply chain coordination among manufacturer and duopolies retailers with recycling facility", The International Journal of Advanced Manufacturing Technology, 87(5-8), pp. 1531-1546 (2016a).

18. Modak, N.M., Modak, N., Panda, S., et al. "Analyzing structure of two-echelon closed-loop supply chain for pricing, quality and recycling management", Journal of Cleaner Production, 171, pp. 512-528 (2017).

19. Modak, N.M., Panda, S., and Sana, S.S. "Threeechelon supply chain coordination considering duopolistic retailers with perfect quality products", International Journal of Production Economics, 182, pp. 564-578 (2016b).

20. Taleizadeh, A.A., Beydokhti, S.R., Cárdenas-Barrón, L.E. "Joint determination of the optimal selling price, refund policy and quality level for complementary products in an online purchasing", European Journal of Industrial Engineering, 12(3), pp. 332-363 (2018a).

21. Xu, L., Li, Y., Govindan, K., et al. "Return policy and supply chain coordination with network-externality effect", International Journal of Production Research, 56(10), pp. 3714-3732 (2018).

22. Modak, N.M., Panda, S., and Sana, S.S. "Pricing policy and coordination for a two-layer supply chain of duopolistic retailers and socially responsible manufacturer", International Journal of Logistics Research and Applications, 19(6), pp. 487-508 (2016c).

23. Roy, A., Sana, S.S., and Chaudhuri, K. "Optimal Pricing of competing retailers under uncertain demand- A two layer, supply chain model", Annals of Operations Research, 260(1-2), pp. 481-500 (2015).

24. Liu, Y., Li, J., Ren, W., et al. "Differentiated products pricing with consumer network acceptance in a dualchannel supply chain", Electronic Commerce Research and Applications, 39, p. 100915 (2020).
25. Yan, R. and Bandyopadhyay, S. "The profit benefits of bundle pricing of complementary products", Journal of Retailing and Consumer Services, 18(4), pp. 355-361 (2011).

26. Mesa-Arango, R. "Algorithms for bundling and pricing trucking services: Deterministic and stochastic approaches", Open Access Dissertations (2015). https://docs.lib.purdue.edu/open_access_dissertations/518

27. Benisch, M. and Sandholm, T. "A framework for automated bundling and pricing using purchase data", In International Conference on Auctions, Market Mechanisms and Their Applications, Springer, Berlin, Heidelberg, pp. 40-52 (2012).

28. Musa, M.I. "Bundling pricing strategy on purchasing decision: A case of Indihome product", Management, 7(3), pp. 126-130 (2017).

29. Pan, L. and Zhou, S. "Optimal bundling and pricing decisions for complementary products in a two-layer supply chain", Journal of Systems Science and Systems Engineering, 26(6), pp. 732-752 (2017).

30. Beladev, M., Rokach, L., and Shapira, B. "Recommender systems for product bundling", KnowledgeBased Systems, 111, pp. 193-206 (2015).

31. Chu, C.S., Leslie, P., and Sorensen, A. "Bundlesize pricing as an approximation to mixed bundling", American Economic Review, 101(1), pp. 263-303 (2011).

32. Jain, S. and Oosterlee, C.W. "The stochastic grid bundling method: Efficient pricing of Bermudan options and their Greeks", Applied Mathematics and Computation, 269, pp. 412-431 (2015).

33. Taleizadeh, A.A., Babaei, M.S., Niaki, S.T.A., et al. "Bundle pricing and inventory decisions on complementary products", Operational Research, 20, pp. 517$541(2020)$

34. Xiao, T. and Shi, J.J. "Pricing and supply priority in a dual-channel supply chain", European Journal of Operational Research, 254(3), pp. 813-823 (2016).

35. Yang, D., Xiao, T., Choi, T.M., et al. "Optimal reservation pricing strategy for a fashion supply chain with forecast update and asymmetric cost information", International Journal of Production Research, 56(5), pp. 1960-1981 (2015).

36. Prasad, A., Venkatesh, R., and Mahajan, V. "Product bundling or reserved product pricing? Price discrimination with myopic and strategic consumers", International Journal of Research in Marketing, 32(1), pp. 1-8 (2015).

37. Taleizadeh, A.A., Cárdenas-Barrón, L.E., Sohani, R. "Coordinating the supplier-retailer supply chain under noise effect with bundling and inventory strategies", Journal of Industrial and Management Optimization, 15(4), pp. 1701-1727 (2019). 


\section{Appendix A}

According to Eq. (3), we have:

$$
\begin{aligned}
& \pi=(w-c)(1-w+k)-k(a+b k) \\
& =w-w^{2}+k w-c+c w-c k-a k-b k^{2}, \\
& \frac{\partial \pi}{\partial w}=0 \Rightarrow 1-2 w+k+c=0 \Rightarrow w=\frac{1+k+c}{2}, \\
& \frac{\partial \pi}{\partial k}=0 \Rightarrow w-c-a-2 b k=0 \Rightarrow k=\frac{w-c-a}{2 b}, \\
& w=\frac{1+k+c}{2} \Rightarrow w=\frac{1+\frac{w-c-a}{2 b}+c}{2} \\
& =\frac{2 b+w-c-a+2 b c}{4 b} \Rightarrow 4 b w-w \\
& =2 b-c-a+2 b c \Rightarrow w^{*}=\frac{2 b c+2 b-c-a}{4 b-1}, \\
& r=\frac{w-c-a}{2 b}=\frac{\frac{1+k+c}{2}-c-a}{2 b}=\frac{1+k+c-2 c-2 a}{4 b} \\
& =\frac{1+k-c-2 a}{4 b} \Rightarrow 4 k b-k=1-c-2 a \Rightarrow k^{*} \\
& =\frac{1-c-2 a}{4 b-1}, \\
& \pi=w-w^{2}+k w-c+c w-c k-a k-b k^{2} \Rightarrow \\
& \pi^{*}=\frac{2 b c+2 b-c-a}{4 b-1}-\left(\frac{2 b c+2 b-c-a}{4 b-1}\right)^{2} \\
& +\left(\frac{1-c-2 a}{4 b-1}\right)\left(\frac{2 b c+2 b-c-a}{4 b-1}\right)-c \\
& +c\left(\frac{2 b c+2 b-c-a}{4 b-1}\right)-c\left(\frac{1-c-2 a}{4 b-1}\right) \\
& -a\left(\frac{1-c-2 a}{4 b-1}\right)-b\left(\frac{1-c-2 a}{4 b-1}\right)^{2} \\
& =\frac{A}{(4 b-1)^{2}}, \\
& A=(4 b-1)(2 b c+2 b-c-a)-(2 b c+2 b-c-a)^{2} \\
& +(1-c-2 a)(2 b c+2 b-c-a)-c(4 b-1)^{2} \\
& +(4 b c-c)(2 b c+2 b-c-a)-(4 b c-c) \\
& (1-c-2 a)-(4 a b-a)(1-c-2 a) \\
& -b(1-c-2 a)^{2}, \\
& A=b^{2} c+8 b^{2}-4 b c-4 a b-2 b c-3 b \\
& +c+a-4 b^{2}-8 b^{2} c+4 b c^{2}+4 b c
\end{aligned}
$$

$$
\begin{aligned}
& +4 a b-2 a c+2 b c+2 b-2 b c^{2}-2 b c \\
& +a c-4 a b+2 a c-2 b c-16 b^{2} c-c \\
& +8 b c+4 b^{2} c^{2}+8 b^{2} c-4 b c^{2}-2 a c \\
& -4 b c+2 b c^{2}+4 a b c-a^{2}-4 a b \\
& +8 a^{2} b-b c^{2}-4 a^{2} b+2 b c+4 a b \Rightarrow \\
A= & 4 b^{2} c^{2}+4 a^{2} b-8 b^{2} c-b c^{2}+4 b^{2}-a^{2}+4 a b c \\
& -4 a b+2 b c-a c+a-b .
\end{aligned}
$$

\section{Appendix B}

According to Appendix A, we have:

$$
\frac{\partial^{2} \pi}{\partial w^{2}}=-2<0, \quad \frac{\partial^{2} \pi}{\partial k^{2}}=-2 b<0 \quad(0<b<1) .
$$

\section{Biographies}

Moaiad Moeany received his BSc degree in Industrial Engineering from Bu-Ali Sina University, Hamedan, Iran and MSc degree in Industrial Engineering from Isfahan University of Technology, Isfahan, Iran. He is a $\mathrm{PhD}$ candidate in Industrial Engineering at University of Tehran. His research interests are pricing and supply chain modeling.

Ata Allah Taleizadeh is an Associate Professor at the School of Industrial Engineering, College of Engineering, University of Tehran in Iran. He received his $\mathrm{PhD}$ in Industrial Engineering from Iran University of Science and Technology. Moreover, he received his $\mathrm{BSc}$ and $\mathrm{MSc}$ degrees both in Industrial Engineering from Islamic Azad University of Qazvin and Iran University of Science and Technology, respectively. His research interest areas include inventory control and production planning, pricing and revenue optimization, and game theory. He has published books, chapter books, and several papers in reputable journals and serves as an editor/editorial board member for a number of international journals.

Fariborz Jolai is currently a Professor of Industrial Engineering at College of Engineering, University of Tehran, Tehran, Iran. He obtained his PhD degree in Industrial Engineering from INPG, Grenoble, France in 1998. He completed his BSc and MSc in Industrial Engineering at Amirkabir University of Technology, Tehran, Iran. His current research interests are scheduling and production planning, supply chain modeling, and optimization problems under uncertainty conditions. 